\title{
The potential effect of Polypodium leucotomos extract on ultraviolet- and visible light-induced photoaging
}

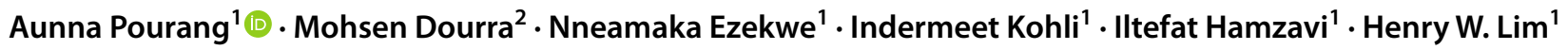

Received: 15 January 2021 / Accepted: 14 July 2021 / Published online: 27 August 2021

(c) The Author(s), under exclusive licence to European Photochemistry Association, European Society for Photobiology 2021

\begin{abstract}
Photoaging induced by both ultraviolet and visible light has been shown to lead to increased inflammation and dysregulation of the extracellular matrix. Standardized extract of the Polypodium leucotomos fern, PLE, possesses anti-inflammatory and antioxidant properties, and has been shown to potentially mitigate photoaging through various mechanisms. This comprehensive review presents the data available on the effects of $P$. leucotomos extract on UV and VL-induced photoaging in vitro as well as in vivo in murine and human models.
\end{abstract}

Keywords Polypodium leucotomos $\cdot$ Photoaging $\cdot$ Visible light $\cdot$ Ultraviolet light

$\begin{array}{ll}\text { Abbreviations } \\ \text { ABTS } & \begin{array}{l}2,2^{\prime} \text {-Azino-bis(3-ethylbenzothiazoline-6-sul- } \\ \text { fonic acid) diammonium salts }\end{array} \\ \text { AP1 } & \text { Activator protein 1 } \\ \text { COX2 } & \text { Cyclooxygenase 2 } \\ \text { CPD } & \text { Cyclobutane pyrimidine dimer } \\ \text { FRAP } & \text { Ferric reducing antioxidant power } \\ \text { H2AX } & \text { H2A histone family member X } \\ \mathrm{H}_{2} \mathrm{O}_{2} & \text { Hydrogen peroxide } \\ \text { HPLC } & \text { High performance liquid chromatography } \\ \text { HSP } & \text { Heat shock protein } \\ \text { i-NOS } & \text { Inducible nitric oxide synthase } \\ \text { IL } & \text { Interleukin } \\ \text { LDH } & \text { Lactate dehydrogenase } \\ \text { MART-1 } & \text { Melanoma antigen recognized by T cells 1 } \\ \text { MED } & \text { Minimal erythema dose } \\ \text { MMP } & \text { Matrix metalloproteinase } \\ \text { NF-kB } & \text { Nuclear factor KB } \\ \text { NRF2 } & \text { Nuclear factor erythroid 2-related factor 2 } \\ \text { NO } & \text { Nitric oxide } \\ \text { TGF- } \beta & \text { Tumor growth factor- } \beta \\ \text { TIMP } & \text { Tissue inhibitor of matrix metalloproteinase }\end{array}$

Henry W. Lim

hlim1@hfhs.org

1 Photomedicine and Photobiology Unit, Department of Dermatology, Henry Ford Health System, 3031 W. Grand Blvd, Suite 800, Detroit, MI 48202, USA

2 College of Medicine, Michigan State University, East Lansing, MI, USA
$\mathrm{TiO}_{2} \quad$ Titanium dioxide

TNF- $\alpha \quad$ Tumor necrosis factor

UCA Urocanic acid

\section{Introduction}

Electromagnetic radiation emitted by sunlight as it reaches the surface of the earth consists of ultraviolet $A$ (320-400 nm) and ultraviolet B (290-320 nm), visible $(400-700 \mathrm{~nm})$, and infrared $(>700 \mathrm{~nm})$ spectra [1]. It is established that UV radiation (UVR) contributes to photoaging, which encompasses the clinical and histological changes from chronic solar radiation exposure due to increased inflammation and oxidative burden. Although not as extensively studied as UVR, visible light (VL) has also been reported to induce photoaging changes [2-6].

The structural integrity of the skin relies on the extracellular matrix (ECM) and its fibrillary proteins, collagen and elastin, which are secreted by fibroblasts [4]. UVR-induced cell membrane lipid oxidation by reactive oxygen species (ROS) leads to the generation of arachidonic acid, which is converted by cyclooxygenase (COX) enzymes into eicosanoids, leading to inflammation [7, 8]. UVR-induced expression of the transcription factor activator protein (AP)-1 leads to ECM damage through over expression of matrix metalloproteinases (MMPs) which degrade collagen and elastin [4, 8-10]. AP-1 also blocks the effect of tumor growth factor (TGF)- $\beta$ which is involved in collagen I and III gene expression and 
synthesis [11]. Photoaging also involves elastase activity, reduced expression of tissue inhibitors of matrix metalloproteinases (TIMPs), fibrillin, and altered cellular stress response proteins, such as heat shock proteins [12]. Histologic changes of photoaging include increased inflammatory cells, elastotic material, glycosaminoglycans and disordered collagen which manifest clinically as wrinkles, and disordered skin remodeling and wound healing $[2,13$, 14]. While much of the information on photoaging has been studied in relation to UVR, VL has also been shown to induce ROS and MMP expression [6].

Although non-tinted topical sunscreens can prevent actinic damage from UVR, they are not protective against VL-induced changes [15]. Traditional sunscreens containing organic ultraviolet (UV) filters have also increasingly been scrutinized for their effects on the environment [16]. These limitations have garnered an increased interest in environmentally safe topical sunscreens and oral polyphenol compounds, the latter to provide systemic protection against a broad wavelengths of solar radiation through increasing plasma and skin antioxidant levels and mitigating the detrimental effects of ROS [17]. The concept of oral antioxidants used as photoprotection, as compared to commonly utilized topical agents, has recently become seriously proposed in the field of photoprotection.

The Polypodium leucotomos fern from the family of Polypodiaceae is found in Central and South America [18]. Standardized extract of P. leucotomos, herein referred to as PLE, is an antioxidant available as an over the counter oral supplement; Polypodium extract as a photoprotectant was patented by **Pathak et al. in 1995 (Patent number: US5614197) and the combination of phenolics and other ingredients observed in this controlled extract were subsequently patented in 2008 and registered as Fernblock $®$ (Cantabria Labs, Madrid, Spain) [19]. Studies have shown that PLE decreases UV-induced erythema, DNA damage, epidermal hyperproliferation, and acute PUVA (psoralen + UVA) induced phototoxic reactions [9, 20-23]. It has been shown to down-regulate the exacerbation of polymorphous light eruption $[24,25]$. The photoprotective properties of oral PLE are thought to be due to its antioxidative and antiinflammatory capacity $[17,26]$.

This comprehensive, in-depth review aims to explore the data available on the effects of P. leucotomos on UV and VL-induced photoaging. This is an update of a previous review published in 2016 [27]. The effects on UV-induced changes will be discussed first, followed by those induced by VL. Each section is will be subdivided into in vitro studies, then animal and human studies. Alterations in molecular photoaging biomarkers as a result of UV or VL irradiation in the skin will be emphasized. It should be noted that except as noted, all studies used PLE preparation of Fernblock ${ }^{\circledR}$ or its precursor.

\section{Studies involving ultraviolet radiation and PLE}

PLE's effects on UV-induced photoaging has been investigated in vitro in human dermal fibroblasts and keratinocytes, and in vivo in murine models and humans (Table 1).

\subsection{In vitro}

In a study by Philips et al., the effects of post-irradiation incubation with PLE on cell membrane damage as measured by LDH, lipid peroxidation, matrix metalloprotease (MMP)-1 and elastin were assessed in UVR (UVA $1.8 \mathrm{~J} / \mathrm{cm}^{2}$ or UVB $2.5 \mathrm{~mJ} / \mathrm{cm}^{2}$ ) irradiated human dermal fibroblasts and human epidermal keratinocytes [10]. PLE was shown to significantly inhibit cellular LDH release from fibroblasts but not from keratinocytes. PLE also significantly inhibited UVR-induced lipid peroxidation and decreased UVR-induced MMP-1 generation from fibroblasts and keratinocytes. Following UVR exposure, an increase generation of elastin was noted from fibroblasts and keratinocytes, regardless of treatment with PLE; however, the PLE-related increase was a reflection of wellformed elastin fiber deposition. The authors postulated that PLE may prevent photoaging by preserving membrane integrity and inhibiting MMP-1 synthesis while reversing intrinsic aging-associated loss of normal elastic fibers [10]. In another study by Philips et al., the effect of various PLE concentrations on collagen and TGF- $\beta$ expression of UV-irradiated (UVA $1.8 \mathrm{~J} / \mathrm{cm}^{2}$ or UVB $2.5 \mathrm{~mJ} / \mathrm{cm}^{2}$ ) human neonatal dermal fibroblasts. Cells were pretreated for $24 \mathrm{~h}$ with PLE doses from 0 to $1 \%$. PLE treatment resulted in increased TGF- $\beta$, type I collagen, and type V collagen levels in the cell media of irradiated fibroblasts. No significant changes were noted in type III collagen expression. These effects on the ECM were thought to be due to PLE's antioxidative properties and possible cell-specific up-regulation of TGF- $\beta$ expression [28].

Philips et al. also evaluated the effect of various PLE concentrations $(0-0.1 \%)$ on generation of elastase, tissue inhibitors of matrix metalloproteinases (TIMPs), fibrillin, TGF- $\beta$, and heat shock proteins (HSP) by keratinocytes after UVR $\left(7.5 \mathrm{~mJ} / \mathrm{cm}^{2}\right.$ UVA or $\left.7.5 \mathrm{~mJ} / \mathrm{cm}^{2} \mathrm{UVB}\right)$. HSP are induced by cellular stress and aid in stabilizing proteins. HSP-27 is linked to epidermal differentiation and HSP-70 is anti-inflammatory and prevents UVB radiation induced epidermal damage [29, 30]. PLE inhibited elastase activity, stimulated TIMP-1, TIMP-2, fibrillin-1, fibrillin-2 and TGF- $\beta$ expression and stimulated synthesis of HSP-27 and HSP-70 by irradiated keratinocytes, thereby strengthening ECM integrity [12]. 
Table 1 Effects of Polypodium leucotomos extract on ultraviolet radiation-induced photoaging in vitro and in vivo

\begin{tabular}{|c|c|c|}
\hline References & Cell types/substrates & Effect of PLE following UV exposure \\
\hline \multicolumn{3}{|l|}{ In vitro studies } \\
\hline Philips et al. [10] & Fibroblasts, keratinocytes & $\begin{array}{l}\downarrow \text { LDH release (fibroblasts only) } \\
\downarrow \text { MMP-1 } \\
\uparrow \text { Elastin }\end{array}$ \\
\hline Philips et al. [28] & Fibroblasts & $\begin{array}{l}\uparrow \text { TGF- } \beta \\
\uparrow \text { Type I collagen } \\
\uparrow \text { Type V collagen }\end{array}$ \\
\hline Philips et al. [12] & Keratinocytes & $\begin{array}{l}\downarrow \text { Elastase } \\
\uparrow \text { TIMP-1 } \\
\uparrow \text { TIMP-2 } \\
\uparrow \text { Fibrillin-1 } \\
\uparrow \text { Fibrillin-2 } \\
\uparrow \text { TGF- } \beta \\
\uparrow \text { HSP-27 and HSP-70 }\end{array}$ \\
\hline Alonso-Lebrero et al. [31] & Fibroblasts, keratinocytes & $\begin{array}{l}\uparrow \text { Cell survival (fibroblasts and keratinocytes) } \\
\uparrow \text { Cell proliferation (fibroblasts and keratinocytes) } \\
\downarrow \text { Cytoskeletal disorganization (fibroblasts only) }\end{array}$ \\
\hline Capote et al. [32] & Trans-urocanic acid, Fibroblasts & $\begin{array}{l}\downarrow \text { Cis-UCA }\left( \pm \mathrm{H}_{2} \mathrm{O}_{2}\right) \\
\downarrow \text { Trans-UCA photodecomposition (in the presence of } \mathrm{TiO}_{2} \text { ) } \\
\uparrow \text { Fibroblast survival }\end{array}$ \\
\hline Janczyk et al. [35] & Keratinocytes & $\begin{array}{l}\downarrow \text { TNF- } \alpha \\
\downarrow N O \\
\downarrow \text { i-NOS } \\
\downarrow N F-k B \\
\downarrow \text { AP1 } \\
\downarrow \text { Loss of cell-cell contacts } \\
\downarrow \text { Abnormalities in cell morphology } \\
\downarrow \text { Cell death } \\
\downarrow \text { Annexin } V \text { binding }\end{array}$ \\
\hline Delgado-Wicke et al. [36] & Keratinocytes & $\begin{array}{l}\uparrow \text { Cell viability } \\
\uparrow \text { Transcription of gene targets of the (NRF2) pathway } \\
\downarrow \text { IL6 and IL8 } \\
\downarrow \text { Induction of melanin production }\end{array}$ \\
\hline Gonzales et al. [38] & $\begin{array}{l}\text { Fibroblasts } \\
\text { Keratinocytes }\end{array}$ & $\begin{array}{l}\uparrow \text { Cell survival } \\
\downarrow D N A \text { damage (H2AX and CPD) }\end{array}$ \\
\hline References & Model & Effect of PLE following UV exposure \\
\hline \multicolumn{3}{|l|}{ In vivo studies } \\
\hline Mulero et al. [39] & Rat & $\begin{array}{l}\uparrow \text { Epidermal catalase } \\
\uparrow \text { Epidermal glutathione peroxidase activity } \\
\uparrow \text { Langerhans cells }\end{array}$ \\
\hline Alcaraz et al. [26] & Mouse & $\begin{array}{l}\downarrow \text { Mast cells } \\
\downarrow \text { Number of capillary loops } \\
\downarrow \text { Dermal elastosis }\end{array}$ \\
\hline Zattra et al. [40] & Mouse & $\begin{array}{l}\downarrow \text { Inflammatory infiltrates } \\
\downarrow \text { Neutrophil infiltration } \downarrow \text { Macrophages } \\
\downarrow \text { COX-2 }\end{array}$ \\
\hline Kohli et al. [22] & Human & $\begin{array}{l}\downarrow \text { COX-2 } \\
\downarrow \text { Erythema }\end{array}$ \\
\hline Middelkamp-Hup et al. [20] & Human & $\downarrow$ Dermal mast cell infiltration \\
\hline Villa et al. [21] & Human & $\downarrow$ Mitochondrial common deletion (trend) \\
\hline Granger et al. $[44]^{\mathrm{a}}$ & Human & $\begin{array}{l}\downarrow \text { Mean FRAP } \\
\downarrow \text { Lipid peroxidation } \\
\uparrow \text { Radiance, moisture, elasticity and skin lightness }\end{array}$ \\
\hline
\end{tabular}

$A P 1$ activator protein 1, COX2 cyclooxygenase 2, CPD cyclobutane pyrimidine dimer, FRAP ferric reducing antioxidant power, $H 2 A X$ H2A histone family member $\mathrm{X}, \mathrm{H}_{2} \mathrm{O}_{2}$ hydrogen peroxide, $\mathrm{HSP}$ heat shock protein, $I L$ interleukin, $i$-NOS inducible nitric oxide synthase, $L D H$ lactate dehydrogenase, $N F-k B$ nuclear factor KB, $N R F 2$ nuclear factor erythroid 2-related factor 2, $N O$ nitric oxide, $M M P$ matrix metalloproteinase, $T G F-\beta$ tumor growth factor- $\beta, T I M P$ tissue inhibitor of matrix metalloproteinase, $\mathrm{TiO}_{2}$ titanium dioxide, $T N F-\alpha$ tumor necrosis factor, $U C A$ urocanic acid

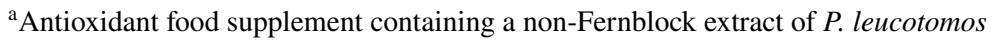


Alonso-Lebrero et al. assessed the effects of PLE on UVA-induced survival and proliferation of human dermal fibroblasts and keratinocytes [31]. Fibroblast morphology was also investigated under these conditions. Cells were irradiated with either UVA or UVB and PLE doses of $0.1-2 \mathrm{mg} / \mathrm{ml}$ were used. Fibroblast survival with PLE was compared to other antioxidants including $\mathrm{N}$-acetylcysteine (NAC), Trolox (a synthetic analog of $\alpha$-tocopherol) or ascorbic acid. PLE induced a noticeable, dose dependent increase in fibroblast survival after irradiation with UVA at $1 \mathrm{~J} / \mathrm{cm}^{2}$ when compared to untreated controls. The other antioxidants preserved fibroblast survival above the untreated controls, but were not as efficient as PLE. PLE also improved the ability of fibroblasts to proliferate after exposure to UVA $\left(1 \mathrm{~J} / \mathrm{cm}^{2}\right)$. Compared to untreated, irradiated fibroblasts, PLE provided complete photoprotection up to $1 \mathrm{~J} / \mathrm{cm}^{2}$ of UVA; the degree of photoprotection declined at doses higher than $1 \mathrm{~J} / \mathrm{cm}^{2}$. PLE protected against UVA-induced $\left(1 \mathrm{~J} / \mathrm{cm}^{2}\right)$ cytoskeletal disorganization and abnormalities in adhesion molecule distribution patterns. PLE with UVA doses of $10 \mathrm{~J} / \mathrm{cm}^{2}$ and $15 \mathrm{~J} / \mathrm{cm}^{2}$ and UVB at $10 \mathrm{~mJ} / \mathrm{cm}^{2}$ demonstrated preserved keratinocyte survival. PLE also demonstrated a protective effect on keratinocyte proliferation at UVA doses of $10 \mathrm{~J} / \mathrm{cm}^{2}$ and $15 \mathrm{~J} / \mathrm{cm}^{2}$. The authors noted that the photoprotection shown for both keratinocytes and fibroblasts suggests that the specificity of PLE is not limited by cell lineage. PLE's ability to block UV-induced cytoskeletal rearrangements also suggests that its photoprotective effect may not only be due to regulation of DNA synthesis, but also cytoskeletal mechanisms [31].

Capote et al. evaluated the effect of various doses of PLE on UVA and UVB-induced photoisomerization of trans-urocanic acid $(t$-UCA; $0.5 \mathrm{mg} / \mathrm{ml})$, a photoreceptor located in the stratum corneum [32]. The cis form of urocanic acid is immunosuppressive and not photoprotective [33]. PLE significantly inhibited UVB $\left(4.8 \mathrm{~J} / \mathrm{cm}^{2}\right)$ and UVA-induced $\left(6.48 \mathrm{~J} / \mathrm{cm}^{2}\right)$ formation of cis-UCA. TransUCA plus $\mathrm{H}_{2} \mathrm{O}_{2}$ irradiated with UVB $\left(4.8 \mathrm{~J} / \mathrm{cm}^{2}\right)$ in the presence of increasing concentrations of PLE $(0-30 \mu \mathrm{g} /$ $\mathrm{ml}$ ) demonstrated a dose-dependent decrease in cis-UCA formation. $\mathrm{H}_{2} \mathrm{O}_{2}$ was used to simulate the presence of endogenous hydroxyl radicals formed by UVB irradiation [34]. $\mathrm{TiO}_{2}$ is known to generate reactive oxygen species (ROS) upon exposure to UV. In the presence of $\mathrm{TiO}_{2}$, PLE significantly decreased levels of UVA $\left(6.48 \mathrm{~J} / \mathrm{cm}^{2}\right)$ induced $t$-UCA photodecomposition. UVA-irradiated $\left(1 \mathrm{~J} / \mathrm{cm}^{2}\right)$ fibroblasts in the presence of PLE demonstrated increased cell survival when compared to untreated irradiated cells. The results demonstrated that PLE may be able inhibit UV-induced $\mathrm{TiO}_{2}$-dependent ROS production and photodecomposition of endogenous photoprotective molecules, such as $t$-UCA [32].
Janczyk et al. evaluated the effects of PLE $1 \mathrm{mg} / \mathrm{ml}$ on levels of TNF- $\alpha$, nitric oxide (NO), inducible nitric oxide synthase (i-NOS), cell membrane damage and cell death, and PLE $0.5-2 \mathrm{mg} / \mathrm{ml}$ on NF-kB and AP1 levels in keratinocytes pre-treated with PLE and irradiated with different doses of UVR. Doses of UVR varied depending on the experiment (UVA $6 \mathrm{~J} / \mathrm{cm}^{2}+\mathrm{UVB} 0.5 \mathrm{~J} / \mathrm{cm}^{2}$, UVA $11 \mathrm{~J} / \mathrm{cm}^{2}+\mathrm{UVB} 1 \mathrm{~J} / \mathrm{cm}^{2} \mathrm{UVA}=2.4 \mathrm{~J} / \mathrm{cm}^{2}+\mathrm{UVB}=0.2 \mathrm{~J} / \mathrm{c}$ $\mathrm{m}^{2}$ ) [35]. PLE pretreatment significantly decreased the upregulation of TNF- $\alpha$, nitric oxide and inducible nitric oxide synthase levels. Comparison of pre and post treatment with PLE demonstrated a significant inhibition of UVR-induced activation of NF-kB, AP1, and partial mitigation of loss of cell-cell contacts, abnormalities in cell morphology, and cell death. In PLE pretreated keratinocytes, a partial counteraction of UV-induced annexin V binding, a marker related to apoptosis, was noted. These findings demonstrated the anti-inflammatory and cell protective effects of PLE against UVR [35].

Delgado-Wicke et al. evaluated the effect of PLE $(7.8-62.5 \mu \mathrm{g} / \mathrm{ml})$ on keratinocytes pre-treated with PLE and subsequently irradiated with UVB $\left(90 \mathrm{~mJ} / \mathrm{cm}^{2}\right)$ or exposed to $\mathrm{PM}_{2.5}(50 \mu \mathrm{g} / \mathrm{ml})$, an experimental model of fine pollutant particles [36]. PLE was found to reduce the decrease in UVB-induced viability of keratinocytes and to induce the transcription of gene targets of the nuclear factor erythroid 2-related factor 2 (NRF2) pathway, which counteracts oxidative stress [37]. UVB-induced interleukin (IL)6 and IL8, as well as induction of melanin production were all decreased by PLE. Similarly, PLE partially reverted $\mathrm{PM}_{2.5}$-induced toxicity of keratinocytes and upregulated NFR2 transcription factor and some of its downstream antioxidant targets. This study demonstrated how PLE protects against not only photooxidative stress but also other environmental pollutants.

Gonzales et al. evaluated the antioxidant capacity of various extracts of Polypodiun leucotomas, and their effects $(1 \mathrm{mg} / \mathrm{ml})$ on UV-induced cell viability and DNA damage in human fibroblasts and keratinocytes irradiated with UVR $\left(2.2 \mathrm{~J} / \mathrm{cm}^{2}\right)$, though the spectral output was not stated in the article [38]. A total of six extracts of Polypodium leucotomas ( 3 from the leaves and 3 from the rhizome portion) were used in this study. The antioxidant moieties protocatechuic, vanillic, caffeic, and ferulic acid were also evaluated by high performance liquid chromatography (HPLC). All samples from the leaves and one sample from the rhizome were found to have significant antioxidant activity as determined by 2,2'-Azino-bis(3-ethylbenzothiazoline-6-sulfonic acid) diammonium salt (ABTS) and ferric reducing antioxidant power (FRAP) assays. Samples 1 and 2, both from leaves, were found to contain detectable amounts of these antioxidant moieties. Samples 1 and 2 were also the most effective in terms of improving cell survival and decreasing DNA damage (decrease in $\gamma$-H2A histone family member $\mathrm{X}$ 
(H2AX) and cyclobutane pyrimidine dimers (CPD)), with sample 2 (Fernblock $\left.{ }^{\circledR}\right)$ being most effective [38].

\subsection{In vivo (murine)}

Mulero et al. assessed the levels of antioxidants and Langerhans cells in the epidermis of hairless rats given oral PLE at a concentration of $30 \mathrm{mg} / \mathrm{kg}$ in drinking water for 7 days, and subsequently irradiated with UVR (UVBUVA-ratio of 0.9; peak at $312 \mathrm{~nm} ; 7 \mathrm{~J} / \mathrm{cm}^{2}$ ) [39]. Dorsal skin biopsies taken $48 \mathrm{~h}$ after irradiation demonstrated a significant increase in epidermal catalase and glutathione peroxidase activity when compared to irradiated animals without PLE, and higher numbers of Langerhans cells compared with the vehicletreated, irradiated group and the control, non-irradiated group. These findings demonstrated the efficacy of PLE as an oral antioxidant and photoimmunoprotective agent [39].

The effect of topical PLE on inflammation and histologic parameters of photoaging in UVB-irradiated hairless albino mice was studied by Alcaraz et al. [26] Mice were divided into control non-irradiated, UVB-irradiated animals without PLE and animals that received topical application of PLE either before (PLE $100 \mathrm{ml}$ of $0.02 \%$ ) or immediately after (PLE $100 \mathrm{ml}$ of $0.2 \%$ ) each UVB exposure (cumulative $1.9 \mathrm{~J} / \mathrm{cm}^{2}$ over 12 weeks). Mice treated with PLE before UVB irradiation showed lower levels of mast cells than those of irradiated control mice. PLE treated mice had a lower number of capillary loops per square millimeter of dermal area indicating decreased inflammation. Inhibition of UV-induced dermal elastosis was also observed in mice receiving topical PLE before and after each UVB irradiation session. These findings demonstrated how PLE ameliorated and partially inhibited some of the histologic damage associated with photoaging [26]. Zattra et al. evaluated the effect of PLE on UVB-induced COX-2 expression and inflammation in the skin of hairless mice. Mice fed with PLE $300 \mathrm{mg} /$ $\mathrm{kg}$ for 10 days and exposed to UVB $\left(25 \mathrm{~mJ} / \mathrm{cm}^{2}\right)$ experienced a decrease in UVB-induced inflammatory infiltrates, neutrophil infiltration, macrophages and COX-2 [40].

\subsection{In vivo (human)}

Kohli et al.evaluated the effect of oral PLE on COX-2 in UV irradiated skin of humans [22]. Twenty-two subjects with Fitzpatrick skin phototype I to III were irradiated with UVB (using 308-nm excimer laser) with doses ranging from 100 to $350 \mathrm{~mJ} / \mathrm{cm}^{2}$. Pre-PLE minimal erythema dose (MED)/ trace erythema assessment and biopsy were performed $24 \mathrm{~h}$ after irradiation. On day 3 subjects took PLE $240 \mathrm{mg} 2 \mathrm{~h}$ and $1 \mathrm{~h}$ (480 $\mathrm{mg}$ total) before irradiation was repeated as on day 1. On day 4 a biopsy was taken from the site of MED/ trace erythema. A statistically significant decrease of COX-2 was found post-PLE consumption $(p<0.0005)$, indicating
PLE's anti-inflammatory effect. A significant improvement in erythema was noted after PLE administration. Overall, the results showed that PLE was able to lessen the negative photobiologic effects of UVB [22]. Middelkamp-Hup et al. studied the effects of PLE on dermal mast cell infiltration after UV irradiation [20]. The back skin of nine participants with Fitzpatrick skin phototype II and III were exposed to UVR (305-400 nm) doses ranging up to 2-3 times the MED dose, before and after taking PLE at different timepoints [20]. After receiving an initial dose of UVR, initial biopsies were taken from pre-PLE irradiated sites from 5 participants after $24 \mathrm{~h}$ and from 2 participants $72 \mathrm{~h}$ after irradiation. The evening before the second exposure of UVR, the first dose of PLE $(7.5 \mathrm{mg} / \mathrm{kg})$ was given to participants. The next day, a second dose of PLE was administered and participants were exposed again at the same UVR fluences $30 \mathrm{~min}, 1 \mathrm{~h}$, $1.5 \mathrm{~h}, 2 \mathrm{~h}$ and $3 \mathrm{~h}$ after the second dose of PLE. A second biopsy was taken from the same participants who had an initial biopsy done from the site at the timepoint showing maximal photoprotection (5 participants after $24 \mathrm{~h}$ and 2 participants $72 \mathrm{~h}$ after irradiation.) Compared to pre-PLE irradiated sites, a reduction in mast cells of the papillary dermis was noted from biopsies taken from post-PLE irradiated sites at either 24 or $72 \mathrm{~h}$ after irradiation [20]. Mast cell products are thought to play a role in photoaging by induction of fibroblast elastin production. The ability of PLE to down-regulate UV-induced mast cell responses suggested that PLE might play a role in reducing changes of photoaging $[20,41]$.

Villa et al. evaluated the effect of PLE on a photoagingassociated mitochondrial common deletion (CD) after UVA irradiation (320-400 $\mathrm{nm}$ with a peak of $350 \mathrm{~nm}$ ) [21]. In this randomized, investigator-blinded, controlled trial, ten participants with Fitzpatrick skin phototype II and III were irradiated with UVA two to three times the MED (using doses of $10-35 \mathrm{~J} / \mathrm{cm}^{2}$ ) either having taken a single dose oral PLE $480 \mathrm{mg}$ before exposure or no PLE. Forearm biopsies taken $24 \mathrm{~h}$ after irradiation demonstrated that at two times the MED, the average CD values decreased by $84 \%$ in the group taking PLE, compared to the $217 \%$ increase over baseline in the non-PLE treated group, trending toward significance $(p=0.06)$. The $\mathrm{CD}$ is a specific mitochondrial DNA deletion induced by chronic UVA radiation in fibroblasts and keratinocytes, and this study's findings suggested that PLE's effect on photodamage may be through preventing UVA-dependent mitochondrial DNA damage [21, 42, 43].

More recently, Granger et al. conducted a clinical trial investigating the effects of an antioxidant food supplement containing a non-Fernblock extract of P. leucotomos on the antioxidant capacity and lipid peroxidation of the skin after UVA irradiation. Thirty participants with Fitzpatrick skin phototype I to III consumed $480 \mathrm{mg}$ daily for 12 weeks and UV irradiation was performed on the 
back skin at various timepoints over 12 weeks to achieve one MED, with doses ranging from 38 to $41 \mathrm{~mJ} / \mathrm{cm}^{2}$. The mean Ferric Reducing Antioxidant Power (FRAP) measurement significantly decreased. Lipid peroxidation was also measured via malondialdehyde (MDA) $4 \mathrm{~h}$ and $24 \mathrm{~h}$ after UVA irradiation $\left(5 \mathrm{~J} / \mathrm{cm}^{2}\right)$ at each visit, and was found to decrease with the supplement. Radiance, moisture, elasticity and skin lightness were also significantly increased after supplementation. The authors concluded that this supplement improved photoprotection, enhanced the antioxidative status of the skin and improved general skin condition [44].

\section{Studies involving visible light and PLE}

While most of the studies related to PLE and photoaging have been done following exposure to UVR, PLE's effects on VL-induced photoaging has also been assessed in vitro in human dermal fibroblasts and in vivo in humans (Table 2).

\subsection{In vitro}

Zamarron et al. assessed various photoaging markers in human dermal fibroblasts pretreated with PLE $(0.5-1 \mathrm{mg} /$ $\mathrm{ml}$ ) and irradiated with VL [45]. Cells exposed to VL $\left(247.3 \mathrm{~J} / \mathrm{cm}^{2}\right)$ without PLE immediately showed signs of cellular stress, such as cytoplasmic retraction and cellular stretching. Cells exposed to VL in the presence of PLE

Table 2 Effects of Polypodium leucotomos extract on visible light-induced photoaging in vitro and in vivo

\begin{tabular}{|c|c|c|}
\hline References & Cell types/substrates & $\begin{array}{l}\text { Effect of } \\
\text { PLE fol- } \\
\text { lowing VL } \\
\text { exposure }\end{array}$ \\
\hline \multicolumn{3}{|l|}{ In vitro studies } \\
\hline Zamarron et al. [45] & Fibroblasts & $\begin{array}{l}\text { Delayed } \\
\text { morpho- } \\
\text { logic } \\
\text { abnor- } \\
\text { malities } \\
\downarrow \text { MMP-1 } \\
\downarrow \text { Cell death } \\
\text { rates } \\
\downarrow \text { Cathepsin- } \\
\text { K (trend) } \\
\uparrow \text { Fibrillins } \\
\uparrow \text { Elastin }\end{array}$ \\
\hline References & Model & $\begin{array}{l}\text { Effect of } \\
\text { PLE fol- } \\
\text { lowing VL } \\
\text { exposure }\end{array}$ \\
\hline \multicolumn{3}{|l|}{ In vivo studies } \\
\hline Mohammad et al. [47] & Human & $\begin{array}{c}\downarrow \text { COX-2 } \\
\downarrow \text { MMP-2 } \\
\text { (trend) } \\
\downarrow \text { MART-1 } \\
\text { (trend) } \\
\downarrow \text { MMP-1 } \\
\text { (trend) } \\
\downarrow \text { MMP-9 } \\
\text { (trend) } \\
\downarrow \text { Persistent } \\
\text { pigment } \\
\text { darkening } \\
\downarrow \text { Delayed } \\
\text { tanning }\end{array}$ \\
\hline Truchuelo et al. [48] & Human & $\downarrow$ MMP-1 \\
\hline
\end{tabular}

COX2 cyclooxygenase 2, MART-1 melanoma antigen recognized by T cells 1, MMP matrix metalloproteinase 
showed similar morphological findings; however, these were not observed until $24 \mathrm{~h}$ after irradiation. PLE also decreased MMP-1 expression compared to that seen in non-PLE treated cells, decreased cell death rates to levels of non-irradiated control cells, and trended toward a decrease in expression of cathepsin-K, a lysosomal cysteine protease that degrades collagen [46]. Fibrillins, structural components of extracellular microfibrils, generally increased with PLE treatment after VL exposure. When compared to control non-irradiated fibroblasts, a significant increase in elastin expression was noted in irradiated fibroblasts, PLE-treated non-irradiated fibroblasts and PLE-treated irradiated fibroblasts. Elastin expression was highest in the highest PLE treatment group. These results indicated that PLE helps prevent VL-induced fibroblast damage, reduces VL-induced ECM degradation enzyme expression and minimizes alterations in VL-induced ECM protein expression [45].

\subsection{In vivo (human)}

Mohammad et al. evaluated the effects of oral PLE on VLinduced photoaging markers. In this prospective clinical trial, 22 volunteers with Fitzpatrick skin types IV through VI were irradiated on their backs with VL doses up to $480 \mathrm{~J} / \mathrm{cm}^{2}$ after administration of $480 \mathrm{mg}$ of PLE per day for 28 days. A statistically significant decrease in COX-2 was reported in PLE treatment skin compared to that irradiated without PLE $(p=0.027)$. A strong trend towards reduction in MMP- 2 was noted, along with a weak trend towards reduction in melanoma antigen recognized by $\mathrm{T}$ cells 1 (MART-1), a melanocytic marker used to assess pigmentation, MMP-1, and MMP-9. Spectroscopic assessments demonstrated a decrease in post-PLE persistent pigment darkening and delayed tanning. These findings reflected the ability of PLE to mitigate VL-induced inflammation, structural integrity and pigmentation [47].

Truchuelo et al. investigated the effect of oral PLE on MMP-1 after irradiation with VL and infrared (IR). In this prospective clinical trial of 7 volunteers, gluteal biopsies were performed on skin irradiated with a single dose of VL $\left(200 \mathrm{~J} / \mathrm{cm}^{2}\right)+$ IR $\left(600 \mathrm{~J} / \mathrm{cm}^{2}\right)$ before and after taking a total oral dose of $960 \mathrm{mg}$ per day of PLE for 21 days. A statistically significant global reduction of MMP- 1 expression was noted by $52 \%$, reflecting PLE's ability to mitigate photoaging-related ECM degradation [48].

\section{Discussion}

Many of the photoprotective effects of PLE in the studies described above are related to its ability to prevent UV and VL-induced ECM degradation by regulating factors involved in ECM remodeling. PLE has been shown to stimulate tissue inhibitor of metalloproteinases (TIMPs), TGF- $\beta$ and Type I, III and V collagen expression in fibroblasts [28] In addition to decreasing MMP-1 expression in keratinocytes and MMP-2 in fibroblasts, PLE also inhibits levels of MMP-1, 3, and 9 enzymes themselves [10,28]. PLE-induced reinforcement of the dermal elastic fiber network in mouse skin and increased elastin expression in VL-irradiated fibroblasts support PLE's potential photoprotective role in counteracting photo-induced elastosis [45, 49]. PLE is well-known for its antioxidative properties which likely also contribute to ECM homeostasis. Rich in polyphenols, such as ferulic and caffeic acid, $P$. leucotomos has been found to scavenge ROS and inhibit UV radiation-induced ROS [50]. In vivo, PLE increases catalase and glutathione peroxidase activity in mice skin [39]. PLE also increases the levels of plasma antioxidants, such as superoxide dismutase (SOD), glutathione S-transferase (GST), and GSH peroxidase (GPx) which likely provides a reservoir of antioxidants to the skin $[49,51,52]$.

PLE's anti-inflammatory properties are demonstrated through its inhibition of UV-induced immunosuppression and inflammatory cells, likely leading to further inhibition of ROS and generation of prostaglandin metabolites, such as COX-2 [22, 26, 32]. The decrease in UVR-induced TNF$\alpha, \mathrm{NO}$, iNOS, NF-kB and AP1 in keratinocytes by PLE are a reflection of its anti-inflammatory anti-apoptotic effects $[35,53,54]$. PLE may also exert its photoprotective effects via the prevention of UV-induced cytoskeletal derangements [31]. In addition, the effect of PLE on phototoxicity and environmental pollutants via the NFR2 antioxidant pathway evidence a possible mechanism by which PLE may protect against other environmental insults that can cause skin aging [36].

Oral PLE is generally well tolerated with minimal adverse effects [51, 52]. The ability of PLE to inhibit the deleterious effect of UV-exposed $\mathrm{TiO}_{2}$ on $t$-UCA and $\mathrm{UVA} / \mathrm{TiO}_{2}-$ induced fibroblast cell death mediated by ROS generation may make it an appropriate adjunct to use in sunscreen formulations [32]. While the studies reviewed above demonstrate several photoprotective properties of PLE, most were done in vitro or with animals. The amount and modes of delivery of PLE as well as doses and forms of radiation differed among studies. Very few studies have been done related to PLE and VL-induced photoaging. Clearly, future large-scale studies assessing the photoprotective effects of oral and topical PLE in humans using natural sunlight over longer periods of time are warranted.

\section{Conclusion}

P. leucotomos may protect against UV and VL-induced photoaging of the skin through regulation of enzymes involved in ECM remodeling, upregulation of ECM 
proteins, downregulation of inflammation and ROS due to its anti-inflammatory and antioxidant properties and cytoprotective effects on fibroblasts and keratinocytes. $P$. leucotomos extract is a well-tolerated and safe agent with photoprotective properties, making it potentially a suitable adjunct in combating UVR and VL-induced skin aging.

Author contributions All authors whose names appear on the submission: 1. Made substantial contributions to the conception or design of the work; or the acquisition, analysis, or interpretation of data; or the creation of new software used in the work; 2. Drafted the work or revised it critically for important intellectual content; 3 . Approved the version to be published; and; 4 . Agree to be accountable for all aspects of the work in ensuring that questions related to the accuracy or integrity of any part of the work are appropriately investigated and resolved.

Funding None provided.

Availability of data and materials Not applicable.

Code availability Not applicable.

\section{Declarations}

Conflict of interest Henry W. Lim has served as investigator/co-investigator for research studies sponsored by Incyte, L'Oréal, Pfizer, and PCORI; he has served as a consultant for Pierre Fabre, ISDIN, Ferndale, Galderma, La Roche-Posay, and Beiersdorf; he has been a speaker on general education sessions for La Roche-Posay, and Cantabria Labs. Iltefat Hamzavi has served as an advisory board member for AbbVie; a consultant for Incyte, Pfizer, and UCB; a principal investigator for AbbVie, Allergan, Bayer, Clinuvel Pharmaceuticals, Este Lauder, Ferndale Laboratories, Galderma Laboratories LP, GE Healthcare, Incyte, Janssen, Janssen Biotech, Johnson \& Johnson, Lenicura, LEO Pharma, Pfizer, and Unigen; a subinvestigator for Amgen, BristolMyers Squibb, Foamix Pharmaceuticals, and Janssen; president of the HS Foundation; and co-chair of the Global Vitiligo Foundation. Indermeet Kohli is an Investigator for Ferndale, Estee Lauder, L'Oreal, Unigen, Johnson and Johnson, Allergan and Bayer with grant received by the institution and is a Consultant for Pfizer, Johnson and Johnson, and Bayer with fee and equipment received by the institution. Aunna Pourang is a subinvestigator for Pfizer, Biofrontera and L'Oreal. Nneamaka Ezekwe is a subinvestigator for Pfizer, Biofrontera and L'Oreal. Mohsen Dourra has no conflicts of interest or disclosures.

Ethical approval Not applicable.

Humans and animals rights Not applicable.

Consent to participate Not applicable.

Consent for publication Not applicable.

\section{References}

1. Frederick, J. E., Snell, H. E., \& Haywood, E. K. (1989). Solar ultraviolet radiation at the earth's surface. Photochemistry and Photobiology, 50(4), 443-450.
2. Scharffetter-Kochanek, K., Brenneisen, P., Wenk, J., et al. (2000). Photoaging of the skin from phenotype to mechanisms. Experimental Gerontology, 35(3), 307-316.

3. Fisher, G. J., Wang, Z. Q., Datta, S. C., Varani, J., Kang, S., \& Voorhees, J. J. (1997). Pathophysiology of premature skin aging induced by ultraviolet light. New England Journal of Medicine, 337(20), 1419-1428.

4. Fisher, G. J., Kang, S., Varani, J., et al. (2002). Mechanisms of photoaging and chronological skin aging. Archives of Dermatology, 138(11), 1462-1470.

5. Cho, S., Lee, M. J., Kim, M. S., et al. (2008). Infrared plus visible light and heat from natural sunlight participate in the expression of MMPs and type I procollagen as well as infiltration of inflammatory cell in human skin in vivo. Journal of Dermatological Science, 50(2), 123-133.

6. Liebel, F., Kaur, S., Ruvolo, E., Kollias, N., \& Southall, M. D. (2012). Irradiation of skin with visible light induces reactive oxygen species and matrix-degrading enzymes. The Journal of Investigative Dermatology, 132(7), 1901-1907.

7. Rinnerthaler, M., Bischof, J., Streubel, M. K., Trost, A., \& Richter, K. (2015). Oxidative stress in aging human skin. Biomolecules, 5(2), 545-589.

8. Nishigori, C. (2006). Cellular aspects of photocarcinogenesis. Photochemical and Photobiological Sciences, 5(2), 208-214.

9. Gonzalez, S., \& Pathak, M. A. (1996). Inhibition of ultravioletinduced formation of reactive oxygen species, lipid peroxidation, erythema and skin photosensitization by Polypodium leucotomos. Photodermatology, Photoimmunology and Photomedicine, 12(2), 45-56.

10. Philips, N., Smith, J., Keller, T., \& Gonzalez, S. (2003). Predominant effects of Polypodium leucotomos on membrane integrity, lipid peroxidation, and expression of elastin and matrixmetalloproteinase- 1 in ultraviolet radiation exposed fibroblasts, and keratinocytes. Journal of Dermatological Science., 32(1), 1-9.

11. Yaar, M., \& Gilchrest, B. A. (2007). Photoageing: Mechanism, prevention and therapy. British Journal of Dermatology, 157(5), 874-887.

12. Philips, N., \& Gonzalez, S. (2013). Beneficial regulation of elastase activity and expression of tissue inhibitors of matrixmetalloproteinases, fibrillin, transforming growth factor- $P$. leucotomos in nonirradiated or ultraviolet-radiated epidermal keratinocytes. ISRN Oxidative Medicine, 2013, 257463.

13. Kligman, L. H., \& Gebre, M. (1991). Biochemical changes in hairless mouse skin collagen after chronic exposure to ultraviolet-A radiation. Photochemistry and Photobiology, 54(2), 233-237.

14. Kaarsen, L. L., Poulsen, T. D., de Fine, O. F., \& Wulf, H. C. (1995). Mast cells and elastosis in ultraviolet-irradiated hairless mice. Photodermatology, Photoimmunology and Photomedicine, $11(1), 1-5$.

15. Lyons, A. B., Trullas, C., Kohli, I., Hamzavi, I. H., \& Lim, H. W. (2020). Photoprotection beyond ultraviolet radiation: A review of tinted sunscreens. Journal of the American Academy of Dermatology, 84, 1393-1397.

16. Schneider, S. L., \& Lim, H. W. (2019). Review of environmental effects of oxybenzone and other sunscreen active ingredients. Journal of the American Academy of Dermatology, 80(1), 266-271.

17. Garcia, F., Pivel, J. P., Guerrero, A., et al. (2006). Phenolic components and antioxidant activity of Fernblock, an aqueous extract of the aerial parts of the fern Polypodium leucotomos. Methods and Findings in Experimental and Clinical Pharmacology, 28(3), 157-160.

18. Choudhry, S. Z., Bhatia, N., Ceilley, R., et al. (2014). Role of oral Polypodium leucotomos extract in dermatologic diseases: A review of the literature. Journal of Drugs in Dermatology, 13(2), $148-153$. 
19. FERNBLOCK® Patented Extract of Polypodium leucotomos. (2020). https://www.cantabrialabsdifacooper.it/tecnologie/fernb lock/. Accessed 26 Aug 2020.

20. Middelkamp-Hup, M. A., Pathak, M. A., Parrado, C., et al. (2004). Oral Polypodium leucotomos extract decreases ultraviolet-induced damage of human skin. Journal of the American Academy of Dermatology, 51(6), 910-918.

21. Villa, A., Viera, M. H., Amini, S., et al. (2010). Decrease of ultraviolet A light-induced "common deletion" in healthy volunteers after oral Polypodium leucotomos extract supplement in a randomized clinical trial. Journal of the American Academy of Dermatology, 62(3), 511-513.

22. Kohli, I., Shafi, R., Isedeh, P., et al. (2017). The impact of oral Polypodium leucotomos extract on ultraviolet B response: A human clinical study. Journal of the American Academy of Dermatology, 77(1), 33-41 e31.

23. Gonzalez, S., Pathak, M. A., Cuevas, J., Villarrubia, V. G., \& Fitzpatrick, T. B. (1997). Topical or oral administration with an extract of Polypodium leucotomos prevents acute sunburn and psoralen-induced phototoxic reactions as well as depletion of Langerhans cells in human skin. Photodermatology, Photoimmunology and Photomedicine, 13(1-2), 50-60.

24. Tanew, A., Radakovic, S., Gonzalez, S., Venturini, M., \& Calzavara-Pinton, P. (2012). Oral administration of a hydrophilic extract of Polypodium leucotomos for the prevention of polymorphic light eruption. Journal of the American Academy of Dermatology, 66(1), 58-62.

25. Caccialanza, M., Recalcati, S., \& Piccinno, R. (2011). Oral Polypodium leucotomos extract photoprotective activity in 57 patients with idiopathic photodermatoses. Giornale Italiano di Dermatologia e Venereologia, 146(2), 85-87.

26. Alcaraz, M. V., Pathak, M. A., Rius, F., Kollias, N., \& González, S. (1999). An extract of Polypodium leucotomos appears to minimize certain photoaging changes in a hairless albino mouse animal model: A pilot study. Photodermatology, Photoimmunology and Photomedicine, 15(3-4), 120-126.

27. Parrado, C., Mascaraque, M., Gilaberte, Y., Juarranz, A., \& Gonzalez, S. (2016). Fernblock (Polypodium leucotomos extract): molecular mechanisms and pleiotropic effects in lightrelated skin conditions, photoaging and skin cancers, a review. International Journal of Molecular Sciences, 17(7), 1026.

28. Philips, N., Conte, J., Chen, Y. J., et al. (2009). Beneficial regulation of matrixmetalloproteinases and their inhibitors, fibrillar collagens and transforming growth factor-beta by Polypodium leucotomos, directly or in dermal fibroblasts, ultraviolet radiated fibroblasts, and melanoma cells. Archives of Dermatological Research, 301(7), 487-495.

29. Jonak, C., Mildner, M., Klosner, G., et al. (2011). The hsp27kD heat shock protein and p38-MAPK signaling are required for regular epidermal differentiation. Journal of Dermatological Science, 61(1), 32-37.

30. Matsuda, M., Hoshino, T., Yamashita, Y., et al. (2010). Prevention of UVB radiation-induced epidermal damage by expression of heat shock protein 70. Journal of Biological Chemistry, 285(8), 5848-5858.

31. Alonso-Lebrero, J. L., Dominguez-Jimenez, C., Tejedor, R., Brieva, A., \& Pivel, J. P. (2003). Photoprotective properties of a hydrophilic extract of the fern Polypodium leucotomos on human skin cells. Journal of Photochemistry and Photobiology $B, 70(1), 31-37$.

32. Capote, R., Alonso-Lebrero, J. L., Garcia, F., Brieva, A., Pivel, J. P., \& Gonzalez, S. (2006). Polypodium leucotomos extract inhibits trans-urocanic acid photoisomerization and photodecomposition. Journal of Photochemistry and Photobiology B, 82(3), 173-179.
33. Finlay-Jones, J. J., \& Hart, P. H. (1998). Photoprotection: Sunscreens and the immunomodulatory effects of UV irradiation. Mutation Research, 422(1), 155-159.

34. Kammeyer, A., Eggelte, T. A., Overmars, H., Bootsma, A., Bos, J. D., \& Teunissen, M. B. (2001). Oxidative breakdown and conversion of urocanic acid isomers by hydroxyl radical generating systems. Biochimica et Biophysica Acta, 1526(3), 277-285.

35. Janczyk, A., Garcia-Lopez, M. A., Fernandez-Penas, P., et al. (2007). A Polypodium leucotomos extract inhibits solar-simulated radiation-induced TNF-alpha and iNOS expression, transcriptional activation and apoptosis. Experimental Dermatology, 16(10), 823-829.

36. Delgado-Wicke, P., Rodríguez-Luna, A., Ikeyama, Y., et al. (2020). Fernblock ${ }^{\circledR}$ upregulates NRF2 antioxidant pathway and protects keratinocytes from PM25-induced xenotoxic stress. Oxidative Medicine and Cellular Longevity, 2020, 2908108.

37. Marrot, L., Jones, C., Perez, P., \& Meunier, J. R. (2008). The significance of Nrf2 pathway in (photo)-oxidative stress response in melanocytes and keratinocytes of the human epidermis. Pigment Cell and Melanoma Research, 21(1), 79-88.

38. Salvador, G., Silvia, R. L., Pablo, D., \& Angeles, J. (2018). Comparison of several hydrophilic extracts of Polypodium leucotomos reveals different antioxidant moieties and photoprotective effects in vitro. Journal of Medicinal Plants Research, 12(22), 336-345.

39. Mulero, M., Rodriguez-Yanes, E., Nogues, M. R., et al. (2008). Polypodium leucotomos extract inhibits glutathione oxidation and prevents Langerhans cell depletion induced by UVB/UVA radiation in a hairless rat model. Experimental Dermatology, 17(8), 653-658.

40. Zattra, E., Coleman, C., Arad, S., et al. (2009). Polypodium leucotomos extract decreases UV-induced Cox-2 expression and inflammation, enhances DNA repair, and decreases mutagenesis in hairless mice. American Journal of Pathology, 175(5), 1952-1961.

41. Gonzalez, S., Moran, M., \& Kochevar, I. E. (1999). Chronic photodamage in skin of mast cell-deficient mice. Photochemistry and Photobiology, 70(2), 248-253.

42. Berneburg, M., Grether-Beck, S., Kurten, V., et al. (1999). Singlet oxygen mediates the UVA-induced generation of the photoagingassociated mitochondrial common deletion. Journal of Biological Chemistry, 274(22), 15345-15349.

43. Berneburg, M., Plettenberg, H., Medve-Konig, K., et al. (2004). Induction of the photoaging-associated mitochondrial common deletion in vivo in normal human skin. The Journal of Investigative Dermatology, 122(5), 1277-1283.

44. Granger, C., Aladren, S., Delgado, J., Garre, A., Trullas, C., \& Gilaberte, Y. (2020). Prospective evaluation of the efficacy of a food supplement in increasing photoprotection and improving selective markers related to skin photo-ageing. Dermatology and Therapy (Heidelberg), 10(1), 163-178.

45. Zamarron, A., Lorrio, S., Gonzalez, S., \& Juarranz, A. (2018). Fernblock prevents dermal cell damage induced by visible and infrared A radiation. International Journal of Molecular Sciences, 19(8), 2250

46. Quintanilla-Dieck, M. J., Codriansky, K., Keady, M., Bhawan, J., \& Runger, T. M. (2009). Expression and regulation of cathepsin $\mathrm{K}$ in skin fibroblasts. Experimental Dermatology, 18(7), 596-602.

47. Mohammad, T. F., Kohli, I., Nicholson, C. L., et al. (2019). Oral Polypodium leucotomos extract and its impact on visible lightinduced pigmentation in human subjects. Journal of Drugs in Dermatology, 18(12), 1198-1203.

48. Truchuelo, M., Jiménez, N., Días, I., Gallego-Rentero, M., Alonso-Juarranz, M., \& Gonzalez, S. (2019). A pilot study to assess the effects of an oral photo protector of botanical origin against visible and infrared radiations in human volunteers. Dermatology and Dermatologic Diseases, 6(2), 1-3. 
49. Rodriguez-Yanes, E., Juarranz, A., Cuevas, J., Gonzalez, S., \& Mallol, J. (2012). Polypodium leucotomos decreases UV-induced epidermal cell proliferation and enhances p53 expression and plasma antioxidant capacity in hairless mice. Experimental Dermatology, 21(8), 638-640.

50. Gomes, A. J., Lunardi, C. N., Gonzalez, S., \& Tedesco, A. C. (2001). The antioxidant action of Polypodium leucotomos extract and kojic acid: Reactions with reactive oxygen species. Brazilian Journal of Medical and Biological Research, 34, 1487-1494.

51. Murbach, T. S., Beres, E., Vertesi, A., et al. (2015). A comprehensive toxicological safety assessment of an aqueous extract of Polypodium leucotomos (Fernblock((R))). Food and Chemical Toxicology, 86, 328-341.
52. Nestor, M. S., Berman, B., \& Swenson, N. (2015). Safety and efficacy of oral Polypodium leucotomos extract in healthy adult subjects. The Journal of Clinical and Aesthetic Dermatology, 8(2), 19-23.

53. Kroncke, K. D., Fehsel, K., Suschek, C., \& Kolb-Bachofen, V. (2001). Inducible nitric oxide synthase-derived nitric oxide in gene regulation, cell death and cell survival. International Immunopharmacology, 1(8), 1407-1420.

54. Ware, C. F., VanArsdale, S., \& VanArsdale, T. L. (1996). Apoptosis mediated by the TNF-related cytokine and receptor families. Journal of Cellular Biochemistry, 60(1), 47-55. 